\title{
THE NOTION OF DRUNKENNESS IN STABLE COMPARISONS IN THE BULGARIAN AND THE RUSSIAN LANGUAGE
}

\section{TEODORA KRASTEVA}

INSTITUTE FOR BULGARIAN LANGUAGE, BULGARIAN ACADEMY OF SCIENCES

tera_kr@abv.bg

This article deals with stable comparisons related to drunkenness in Bulgarian and Russian. The material excerpted from texts from the Bulgarian National Corpus and the Russian National Corpus is studied in comparative terms. Relations of different equivalence are established.

Keywords: linguocultural studies, stable comparisons, Bulgarian language, Russian language, drunkenness, corpus-based studies

\section{REFERENCES}

Balgarski natsionalen korpus. $<$ http://search.dcl.bas.bg/> [pregledan 18.12.2018].

Holandi 2008: Holandi, R. Ustoychivi sravnenia. Balgarski, ruski, angliyski, nemski, frenski. Blagoevgrad, Universitetsko izd. „Neofit Rilski“, $472 \mathrm{~s}$.

Holandi 2012: Holandi, R. Semantichna blizost, opozitsia i polisemia pri zoonimnite frazeologichni edinitsi v angliyskia i balgarskia ezik. OPERA SLAVICA, XXII, 2.

Kartalova 2013: Kartalova, M. Ustoychivi sravnenia s komparatum nedomestitsiran zhivotinski vid v balgarskia i novogratskia ezik. - Nauchni trudove, t. 51, kn. 1, sb. B - Filologiya.

Krasteva 2017: Krasteva, T. Ustoychivite sravnenia kato obekt na lingvokulturologiyata. - Balgarski ezik (64), 1, 87-94. <http://www.balgar-skiezik.eu/1-2017/ T-KRASTEVA-87-94-full.pdf $>$.

Krasteva 2016: Krasteva, Zh. Ustoychivi sravnenia s intenzifitsirasht harakter v balgarskia i frenskia ezik. - http://ireteslaw.ispan.waw.pl/bitstream/handle/

Kyuvlieva-Mishaykova 1986: Kyuvlieva-Mishaykova, V. Ustoychivite sravnenia v balgarskia ezik. Sofia, Izd. na BAN.

Lebedeva 2015: Lebedeva, L. A. Ustojchivye sravnenija russkogo jazyka. Tematicheskij slovar'. Moskva, Flinta, Nauka.

Legurska 2015: Legurska, $P$. Sapostavitelni analizi i natsionalna spetsifika na leksikata, Sofia, Eto, $190 \mathrm{~s}$.

Legurska 1983: Legurska, $P$. Ustojchivye sravnenija s komparativnym komponentom - nazvanie zhivotnogo $\mathrm{v}$ russkom i bolgarskom jazykah. - Bolgarskaja russistika, 3, s. 46-51. 
Legurska 1982: Legurska, P. Vtorichnye leksicheskie nominacii konkretnyh imen sushhestvitel'nyh v russkom i bolgarskom jazykah. Sofia, Sofiyski universitet, 1983. 289 s. Disertatsia za nauchnata stepen „kandidat na filologicheskite nauki““.

Legurska, Krasteva 2019: Legurska, P., T. Krasteva. Katalogizirane na ustoychivite sravnenia $\mathrm{v}$ balgarskia ezik (varhu material ot Balgarskia natsionalen korpus) kato obekt na lingvokulturologiyata. - Balgarski ezik (66), 2, s. 107-119.

Legurska, Panchev 2014: Legurska, P., I. Panchev. Obrazni metafori (onomasiologichen katalog) - Dzyalo, god. II, broy 2. [pregledan 10.10.2018] <http://www. abcdar.com/docs/magazine/2/Legurska_Panchev.pdf>.

Mokienko, Sidorenko 2005: Mokienko V. M., K. P. Sidorenko. Shkol'nyj slovar' krylatykh vyrazhenij Pushkina. SPb, Neva, 276 s.

Ogolcev 1979: Ogol'cev, V. M. Ustojchivye sravnenija v sisteme russkoj frazeologii. Leningrad.

Ogolcev 2001: Ogol'cev, V. M. Slovar' ustojchivyh sravnenij russkogo jazyka (sinonimo-antonimicheskij). M.

Rechnik na balgarskia ezik. <http://ibl.bas.bg/rbe/> [pregledan 16.12.2018].

Ruski natsionalen korpus. < http://www.ruscorpora.ru/> [pregledan 16.12.2018].

Vitanova 2011: Vitanova, $M$. Vanshniyat vid na balgarina, otrazen v ustoychivite sravnenia. - Mnogoobrazie v edinstvoto. Istoria i savremennost. 2, s. 285-290. $<\mathrm{http}$ //tksi.org/SUB/papers/2-2/2-2-40.pdf $>$.

Yanev 2013: Yanev, B. Obraznite sravnenia s antropotsentrichen harakter v balgarskia i angliyskia ezik. Izsledvane i rechnik. Plovdiv, Paisiy Hilendarski.

$\triangle$ Teodora Krasteva

Department of Ethnolinguistics

Institute for Bulgarian Language, Bulgarian Academy of Sciences 52 Shipchenski prohod blvd., bl. 17, 1113 Sofia, Bulgaria 